\title{
Right upper lobe segmentectomy guided by simplified anatomic models
}

Seshiru Nakazawa, MD, ${ }^{\mathrm{a}}$ Kimihiro Shimizu, MD, ${ }^{\mathrm{b}}$ Natsuko Kawatani, MD, ${ }^{\mathrm{a}}$ Kai Obayashi, MD, ${ }^{\mathrm{a}}$ Yoichi Ohtaki, MD, ${ }^{\mathrm{a}}$ Toshiteru Nagashima, MD, ${ }^{\mathrm{a}}$ Takashi Eguchi, MD, ${ }^{\mathrm{b}}$ Toshiki Yajima, MD, ${ }^{\mathrm{a}, \mathrm{c}}$ and Ken Shirabe, $\mathrm{MD}^{\mathrm{a}}$

\section{ABSTRACT}

Background: To standardize the technical strategy for right upper lobe (RUL) segmentectomy, we previously developed simplified 3-dimensional (3D) anatomic models that classify the RUL anatomy into 14 patterns according to the branching pattern of bronchi and veins. We aimed to study the surgical outcome of RUL segmentectomy guided by these simplified anatomic models.

Methods: Patients were classified into the anatomic models, and the approach to the intersegmental veins was selected accordingly. The intersegmental vein and corresponding intersegmental plane were as follows: $V^{\top} b$ (the apicoanterior plane), $\mathrm{V}^{2} \mathrm{a}$ (the apicoposterior plane), and $\mathrm{V}^{2} \mathrm{c}$ (the posteroanterior plane). Clinicopathologic characteristics and short- and long-term outcomes were analyzed retrospectively.

Results: Thirty-four consecutive patients who underwent thoracoscopic RUL segmentectomy guided by simplified anatomic models between January 2016 and December 2019 at Gunma University were analyzed. All the patients were classified into a model: anterior + central lab type (47\%), anterior + central Ib type $(41 \%)$, anterior II type $(12 \%)$, or central III type (O\%). The standard approaches to intersegmental veins were an anterior approach for $\mathrm{V}^{1} \mathrm{~b}$, a posterobronchial approach for $\mathrm{V}^{2} \mathrm{a}$, and an interlobar approach for $\mathrm{V}^{2} \mathrm{c}$. The approach to intersegmental or intrasegmental veins was modified according to the anatomic model in 4 cases $(12 \%)$. The median operative time, blood loss, and hospital stay were 222 minutes, 19 grams, and 7 days, respectively. Prolonged air leakage was observed in 1 patient.

Conclusions: Segmentectomy guided by simplified anatomic models promotes anatomic classification, development of a standardized approach for segmental vein identification, and acceptable outcomes, which can facilitate the implementation of RUL segmentectomy. (JTCVS Techniques 2020;4:288-97)

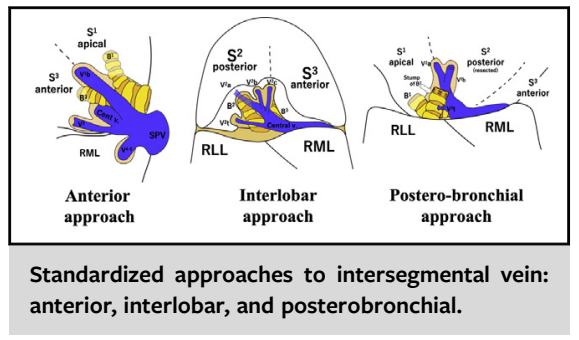

CENTRAL MESSAGE

Right upper lobe segmentec-

tomy guided by anatomic

models allows the classification

of segmental anatomy, a stan-

dardized approach to the inter-

segmental veins, and successful completion of segmentectomy.

\section{PERSPECTIVE}

Right upper lobe (RUL) segmentectomy remains challenging, given the complex segmental anatomy and spatial relationship between the bronchus and vessels. RUL segmentectomy guided by anatomic models facilitates the precise classification of anatomy, development of a standardized approach to intersegmental veins, and successful completion of segmentectomy.

See Commentaries on pages 298 and 299.
From the ${ }^{\mathrm{a}}$ Department of General Surgical Science, Gunma University, Graduate School of Medicine, Maebashi; ${ }^{\mathrm{b}}$ Division of General Thoracic Surgery, Department of Surgery, Shinshu University School of Medicine, Matsumoto; and ${ }^{\mathrm{C} D e p a r t-}$ ment of Innovative Cancer Immunotherapy, Gunma University, Graduate School of Medicine, Maebashi, Japan.

Drs Nakazawa and Shimizu contributed equally to this work and should be considered co-first authors.

Received for publication July 29, 2020; revisions received July 29, 2020; accepted for publication Aug 10, 2020; available ahead of print Aug 13, 2020.

Address for reprints: Kimihiro Shimizu, MD, Division of General Thoracic Surgery, Department of Surgery, Shinshu University School of Medicine, Asahi, Matsumoto, Nagano 390-8621, Japan (E-mail: kmshimizu@ shinshu-u.ac.jp).

2666-2507

Copyright (c) 2020 The Authors. Published by Elsevier Inc. on behalf of The American Association for Thoracic Surgery. This is an open access article under the CC BY-NC-

ND license (http://creativecommons.org/licenses/by-nc-nd/4.0/).

https://doi.org/10.1016/j.xjtc.2020.08.018 $\square$ Video clip is available online.

Studies have shown that one-third of lung cancers develop in the right upper lobe (RUL). ${ }^{1}$ Owing to the increased rate at which small and early-stage lung cancers are being detected via computed tomography (CT) screening, ${ }^{2}$ the need for RUL segmentectomy has been rapidly increasing. However, techniques vary greatly, depending on the surgeon's experience or hospital's infrastructure. ${ }^{3}$ In addition, RUL segmentectomies are considered more complex compared with typical segmentectomies of the superior, 


\section{Abbreviations and Acronyms \\ $3 \mathrm{D}=3$-dimensional \\ $\mathrm{CT}=$ computed tomography \\ RUL $=$ right upper lobe}

basilar, lingular, or upper division, owing to greater technical difficulties and anatomic variations. ${ }^{4}$

Successful segmentectomy requires intraoperative identification of intersegmental veins, which run through the intersegmental plane.$^{5-7}$ However, identifying the intersegmental vein is often difficult owing to anatomic variations. ${ }^{8}$ The RUL consists of 3 intersegmental veins (Figure 1): $V^{1} b$, running through the apicoanterior segmental plane (between $\mathrm{S}^{1}$ and $\left.\mathrm{S}^{3}\right) ; \mathrm{V}^{2}$ a, running through the apicoposterior segmental plane (between $S^{1}$ and $S^{2}$ ); and $V^{2}$ c, running through the posteroanterior segmental plane (between $\mathrm{S}^{2}$ and $\mathrm{S}^{3}$ ).

We previously analyzed the right lung anatomic pattern using 3-dimensional (3D) CT images in $>250$ patients. ${ }^{9,10}$ Although several variants exist, RUL anatomy can be classified into 4 types based on the drainage pattern of the anterior and central pulmonary veins. ${ }^{9,11}$ In our clinical practice, we have been classifying lung anatomy based on these simplified anatomic models and use a methodological approach for identifying the intersegmental veins according to model subtype. In the present study, we aimed to investigate the surgical outcomes of RUL segmentectomy performed under this anatomic model classification and model-based approach to the intersegmental veins.

\section{METHODS}

\section{Patients and Variables}

We performed a retrospective study of all patients who underwent RUL segmentectomy between January 2016 and December 2019 at

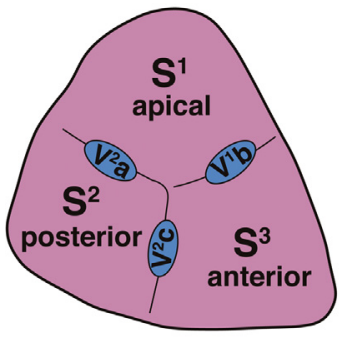

Intersegmental veins

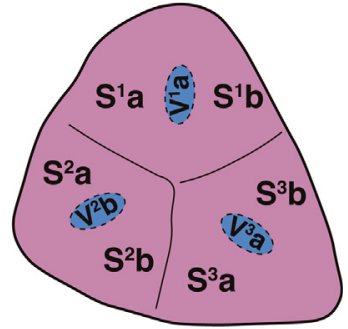

Intrasegmental veins
FIGURE 1. Numerical naming style for pulmonary segments and veins of the right upper lobe. $\mathrm{S}^{1}, \mathrm{~S}^{2}$, and $\mathrm{S}^{3}$ denote the apical, posterior, and anterior segments, respectively. The 3 intersegmental veins are designated $V^{1} b$, running through the apicoanterior segmental plane (between $S^{1}$ and $S^{3}$ ); $\mathrm{V}^{2} \mathrm{a}$, running through the apicoposterior segmental plane (between $S^{1}$ and $\mathrm{S}^{2}$ ); and $\mathrm{V}^{2} \mathrm{c}$, running through the posteroanterior segmental plane (between $S^{2}$ and $S^{3}$ ). $V^{1} a, V^{2} b$, and $V^{3}$ a are the intrasegmental veins running through the center of $S^{1}, S^{2}$, and $S^{3}$, respectively.
Gunma University. The study was approved by the Institutional Review Board of Gunma University Hospital (protocol HS2019-279) and was conducted in accordance with the principles of the Declaration of Helsinki. The need for written informed consent from each patient was waived.

We included patients who had undergone thoracoscopic anatomic model-guided segmentectomy and excluded those who had undergone thoracotomy or additional use of CT-guided preoperative marking. The patients underwent preoperative imaging (CT scan, positron emission tomography/CT, and brain magnetic resonance imaging) for clinical staging and spirometry for functional evaluation. Charts were reviewed for age, sex, RUL anatomic model type, main location of lung lesion, comorbidities, preoperative diagnosis, consolidation/tumor ratio, pathological diagnosis, and surgical outcome. The surgical outcome encompassed operative time, bleeding, duration of chest tube placement, postoperative hospital stay, complications, and 90-day mortality. The main location of the tumor was identified using conventional $\mathrm{CT}$ and $3 \mathrm{D}-\mathrm{CT}$ images, according to the spatial relationship with bronchi and intersegmental veins. Successful completion of segmentectomy was defined as follows: completion of segmentectomy as planned preoperatively using anatomic models and negative surgical margin at the time of final pathological diagnosis.

\section{Selection Criteria for Segmentectomy}

Sublobar resection (segmentectomy or wedge resection) was performed for patients considered to have noninvasive lung cancer (defined as a lung lesion $\leq 2.0 \mathrm{~cm}$ with a consolidation/tumor ratio $\leq 0.5),{ }^{12,13}$ a metastatic lung lesion, or a lung lesion without a definite preoperative diagnosis. According to the criteria proposed by the guideline committee of the Japanese Association for Chest Surgery, sublobar resection was also performed for those who could not undergo standard lobectomy because of limited cardiopulmonary reserve. ${ }^{14}$ The choice of segmentectomy or wedge resection was based on the location and radiologic features of the lung nodule. In brief, wedge resection was performed for palpable nodules located at the surface of the lung, and segmentectomy was performed for impalpable nodules or those located deep in the lung parenchyma or close to the hilum. For cases of suspected malignancy, a resection that allowed for a surgical margin $>2 \mathrm{~cm}$, or larger than the tumor diameter for centrally-localized nodules, was planned. Bisegmentectomy or segmentectomy combined with subsegmentectomy was performed for lesions located at the border of a segment. Resected specimens were examined histopathologically and classified according to the World Health Organization's classification scheme. Staging was performed according to the TNM Classification of Malignant Tumors.

\section{Pulmonary Segments and Veins in the RUL}

In this study, we used a numerical naming system for pulmonary segments and veins (Figure 1). Accordingly, $S^{1}, S^{2}$, and $S^{3}$ represent the apical, posterior, and anterior segment, respectively ${ }^{8} ; \mathrm{V}^{1} \mathrm{a}, \mathrm{V}^{2} \mathrm{~b}$, and $\mathrm{V}^{3}$ a represent the intrasegmental vein running through the center of $S^{1}, S^{2}$, and $S^{3}$, respectively; and $\mathrm{V}^{1} \mathrm{~b}, \mathrm{~V}^{2} \mathrm{a}$, and $\mathrm{V}^{2} \mathrm{c}$ represent the intersegmental vein running through the intersegmental plane between $S^{1}$ and $S^{3}, S^{1}$ and $S^{2}$, and $S^{2}$ and $\mathrm{S}^{3}$, respectively.

\section{D Image Reconstruction and Classification Into a Simplified Anatomic Model}

3D images were reconstructed from CT images obtained using a 64channel multidetector row CT scanner (SOMATOM Definition Flash; Siemens Healthcare, Erlangen, Germany). A total of $35 \mathrm{~mL}$ of contrast agent was injected at $5 \mathrm{~mL} / \mathrm{s}$, immediately followed by the injection of $20 \mathrm{~mL}$ of saline. A solid image was constructed from 1.0-mm data slices of contrast-enhanced CT images using a volume-rendering software (Ziostation; Ziosoft, Tokyo, Japan), as described previously. ${ }^{9}$ Based on our previous analysis, the accuracy of the 3D-CT reconstruction of the 


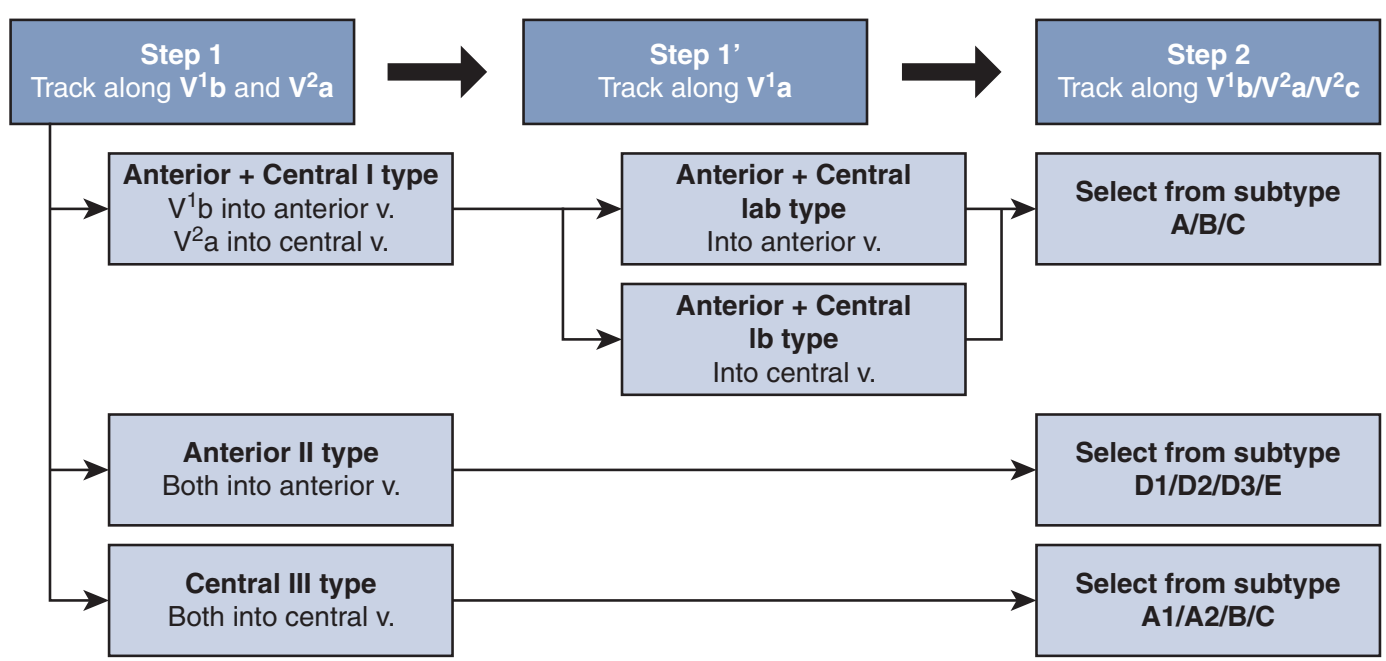

3D-CT images
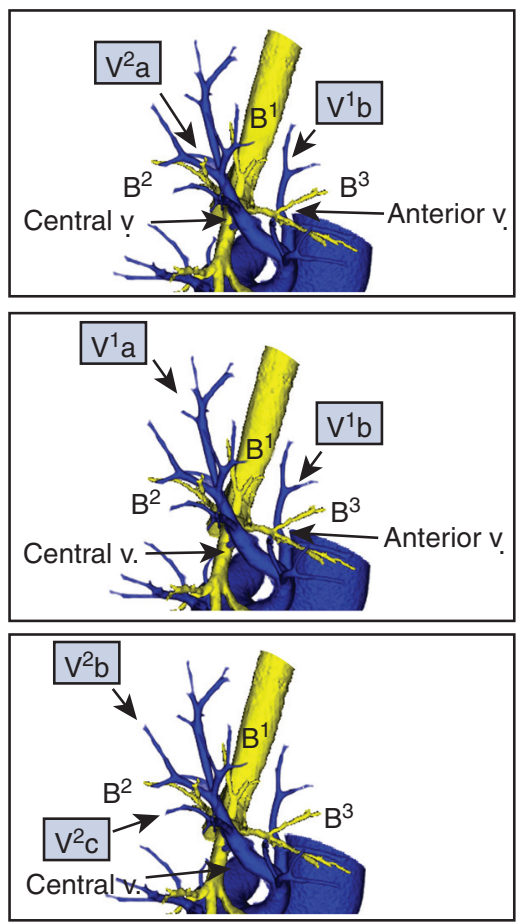

Anatomic model
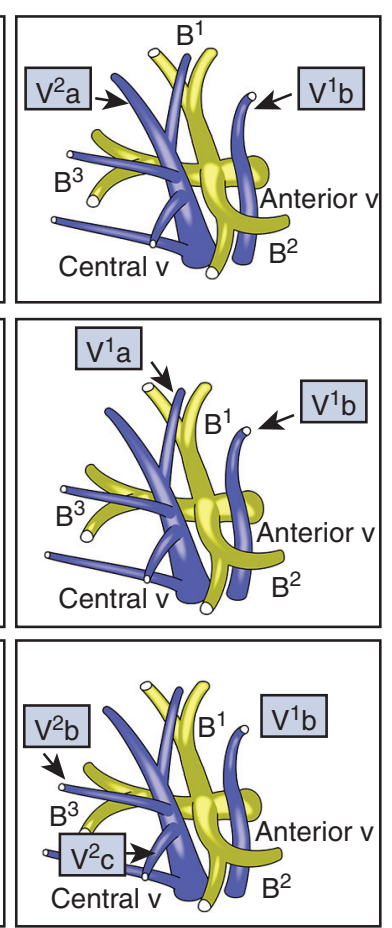

Step for classification

\section{Step 1 Track along $V^{1} b$ and $V^{2} a$}

$V^{1} b\left(S^{1} / S^{3}\right.$ intersegmental $v$.) runs into anterior $v$.

$V^{2} a\left(S^{1} / S^{2}\right.$ intersegmental v.) runs into central $v$.

$\rightarrow$ Anterior + Central I type

FIGURE 2. Two-step classification of RUL anatomic models. Flowchart for the 2-step classification of anatomic models and example of classification (anterior + central Ib-A type). Step 1: Classification into 1 of the 3 major models. $\mathrm{V}^{1} \mathrm{~b}$ and $\mathrm{V}^{2} \mathrm{a}$ are tracked down to identify the anterior and central vein. The anterior vein usually originates from $\mathrm{V}^{1} \mathrm{~b}$, runs through the anterior side of the RUL bronchus, and finally drains into the superior pulmonary vein from the mediastinal side. The central vein usually originates from $\mathrm{V}^{2} \mathrm{a}$, runs through the central part of the RUL between $\mathrm{B}^{2}$ and $\mathrm{B}^{3}$, and finally drains into the superior pulmonary vein from the interlobar side. Step $1^{\prime}$ : Classification into Iab or Ib type (for anterior + central I type). The drainage pattern of $\mathrm{V}^{1} \mathrm{a}$ is tracked down. If $\mathrm{V}^{1}$ a drains into the anterior vein with $\mathrm{V}^{1} \mathrm{~b}$, the anatomy is classified as Iab type. If only $\mathrm{V}^{1} \mathrm{~b}$ drains into the anterior vein, it is classified as Ib type. Step 2: Classification into subtypes. Each major anatomic model is further subclassified into 3 to 4 subtypes according to the drainage pattern of intersegmental veins $\mathrm{V}^{1} \mathrm{~b}, \mathrm{~V}^{2} \mathrm{a}$, and $\mathrm{V}^{2} \mathrm{c}$. Central v., Central vein; anterior v., anterior vein; $C T$, computed tomography.

bronchovascular structure is $98.7 \% .^{9}$ Each patient was classified into anatomic models by a 2 -step process (Figures 2 and 3). The first step consisted of classification into 1 of the 4 major anatomic models based on the drainage pattern of the RUL's principal veins, the anterior and central veins. ${ }^{11}$ The second step included subclassification into 1 of the 14 subtypes, according to the drainage pattern of the intersegmental veins and the spatial relationship among segmental veins. $\mathrm{V}^{3}$ was not included in these models, because it is not an intersegmental vein and its drainage pattern is diverse (ie, drains more proximally than the anterior or central veins or drains into $\mathrm{V}^{4}$ and $\mathrm{V}^{5}$ ). 


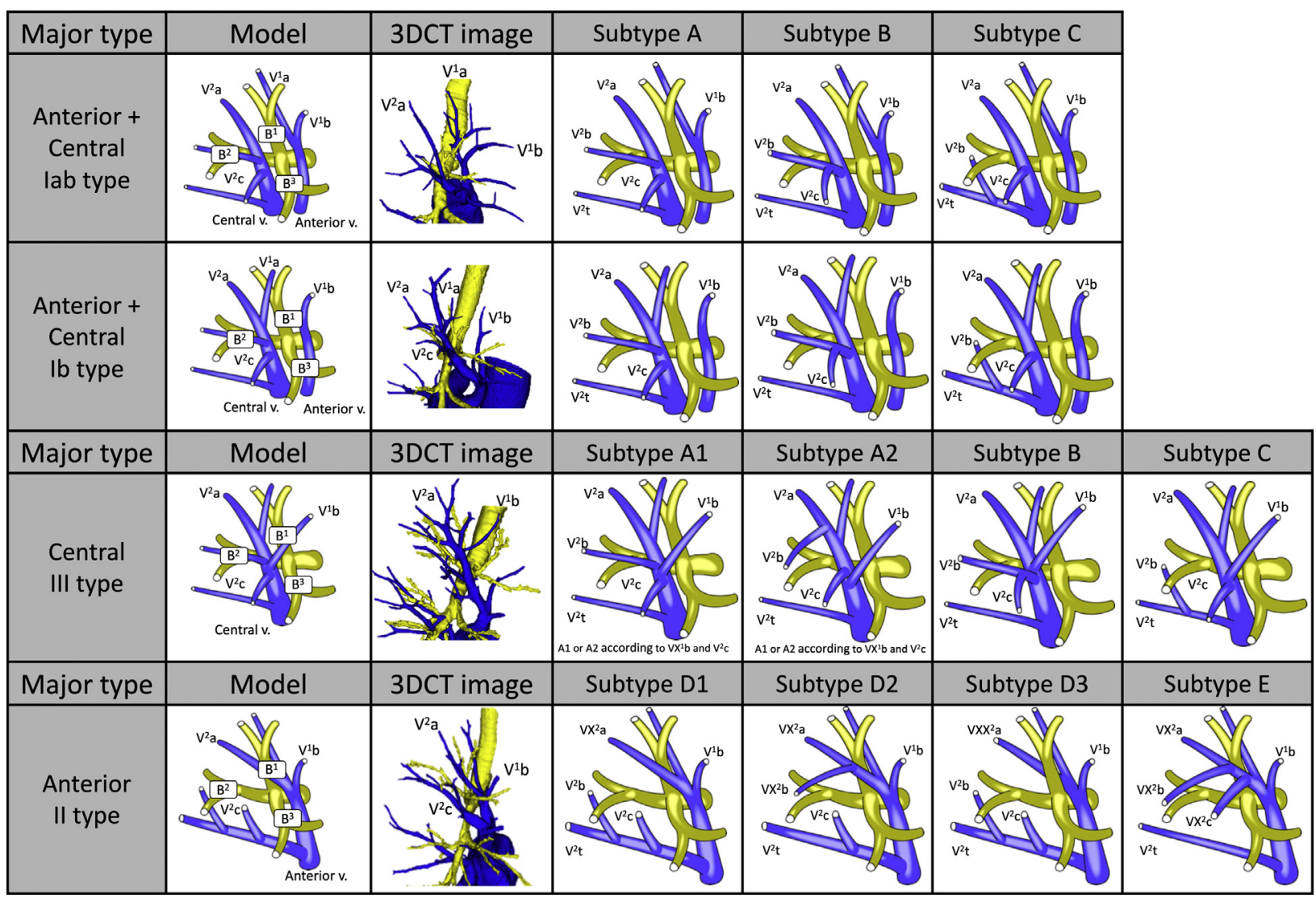

FIGURE 3. Reference sheet for the 14 anatomic model subtypes. Anterior + central Iab, Ib type, and central III type were subclassified into subtypes A, B, and $C$, respectively, according to the drainage patterns of $V^{2} b$ and $V^{2} c$. For the central III type, subtype $A$ was named subtype $A 1$ when $V^{1} b\left(V X^{1} b\right)$ drained into $\mathrm{V}^{2}$ a more peripherally than $\mathrm{V}^{2} \mathrm{c}$ and was named subtype $\mathrm{A} 2$ when $\mathrm{V}^{1} \mathrm{~b}$ drained into $\mathrm{V}^{2}$ a more centrally than $\mathrm{V}^{2} \mathrm{c}$. Anterior II type was classified into subtypes D1, D2, D3, and E according to the drainage pattern of $\mathrm{V}^{2} \mathrm{a}$ (or $\mathrm{VX}^{2} \mathrm{a}, \mathrm{VXX}^{2} \mathrm{a}$ ), $\mathrm{V}^{2} \mathrm{~b}$ (or VX $\mathrm{V}^{2} \mathrm{~b}$ ), and $\mathrm{V}^{2} \mathrm{c}$ (or VX $\mathrm{V}^{2}$ ). Central v., Central vein; anterior v., anterior vein; $C T$, computed tomography.

This classification system focuses on the intersegmental veins for several reasons. First, the intersegmental veins are structures that physically define the boundaries of the segments, and thus they are used for preoperative planning to determine whether the surgical margin between the tumor and segmental border is sufficient or whether a (sub)segmentectomy is required. Second, the proximal part of the intersegmental plane created by other adjuncts, such as jet ventilation and/or injection of indocyanine green, is unclear at the hilum, close to the bronchus. Therefore, dissection of the intersegmental plane at the hilum is usually done along these intersegmental veins, especially when operating for small metastatic lung tumors located proximal to the hilum. Third, the peripheral parts of the intersegmental plane defined by other adjuncts are occasionally unclear. In such cases, additional guidance by the intersegmental veins is essential for determining the intersegmental plane. These features of the intersegmental veins are crucial during anatomic segmentectomy and cannot be compensated for by solely focusing on bronchus or arteries.

\section{Surgical Procedure}

RUL segmentectomy was planned according to the targeted segment and anatomic model subtype (Figures 3 and 4). In particular, we focused on the intersegmental veins and the approach for identifying them (Figure 4). The patient's anatomy was classified into one of the anatomic models, after which 3D-CT images were used to identify segmental arteries planned for resection and their spatial relationship with the bronchus and veins of the anatomic model. The anatomy was intraoperatively compared with the 3D-CT images to avoid misidentification of anatomic structures.

Our basic technique for segmentectomy has been described previously. ${ }^{6}$ The central portion of the intersegmental plane was dissected along the intersegmental veins in all cases. Intersegmental veins running through the surface of the lung parenchyma were identified from the anterior side of the hilum (anterior approach) or from the interlobar fissure (interlobar approach), whereas intersegmental veins running deep within the lung parenchyma were identified after resection of the targeted segmental bronchus (posterobronchial approach) (Figure 5). The standard approaches for $\mathrm{V}^{1} \mathrm{~b}, \mathrm{~V}^{2} \mathrm{a}$, and $\mathrm{V}^{2} \mathrm{c}$ were the anterior, posterobronchial, and interlobar approaches, respectively. Different approaches were used in patients with anatomic variants in their intersegmental veins.

The peripheral portion of the intersegmental plane was dissected along the inflation-deflation line created by selective jet ventilation of the targeted segmental bronchus and/or along the demarcation line created by the intravenous injection of indocyanine green after resection of the targeted pulmonary arteries. In selective jet ventilation, we introduced the bronchoscope into the target bronchus, fixed the bronchoscope by clamping the bronchus using forceps, and performed jet ventilation until complete inflation of the target segment. The intersegmental plane was resected either by electrocautery or stapling (Videos 1 and 2). Compared with stapling, dissection of the intersegmental plane by electrocautery alone could lead to air leakage when performed incorrectly along the intersegmental plane. Therefore, stapling was selected preoperatively 


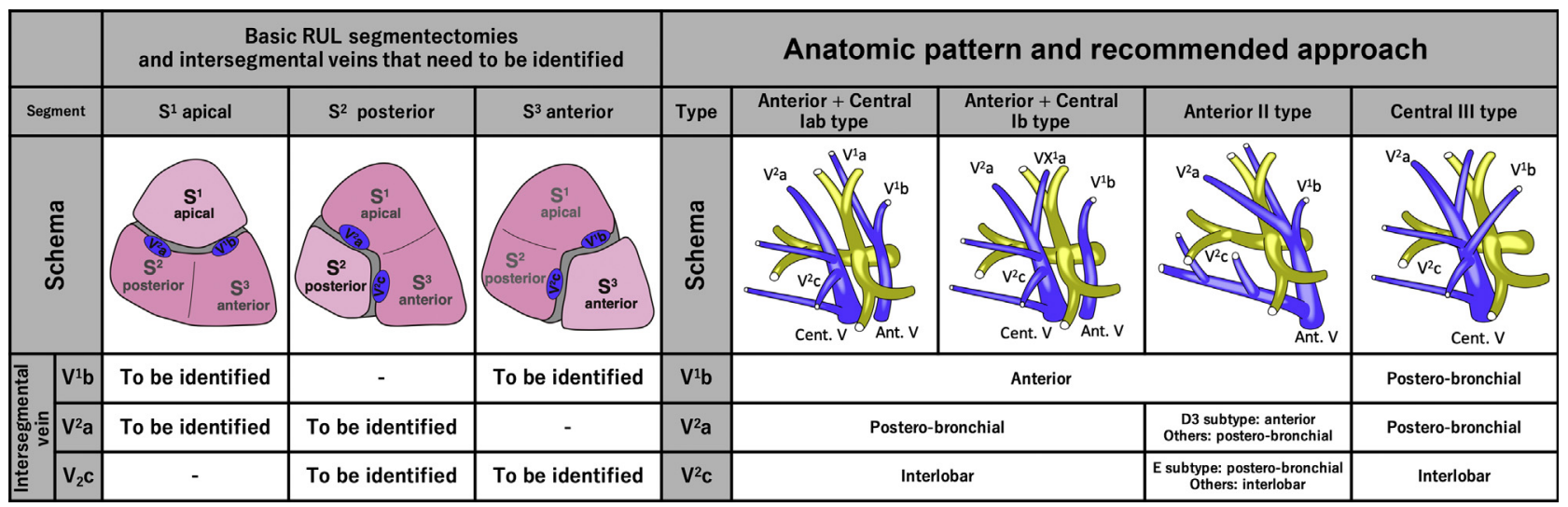

FIGURE 4. Recommended approach to intersegmental veins according to the targeted segment and anatomic model. (Left) The 3 basic RUL segmentectomies and the intersegmental veins (blue-colored) that need to be identified: $\mathrm{V}^{1} \mathrm{~b}$ and $\mathrm{V}^{2}$ a for apical $\mathrm{S}^{1}$ segmentectomy, $\mathrm{V}^{2}$ a and $\mathrm{V}^{2} \mathrm{c}$ for posterior $\mathrm{S}^{2}$ segmentectomy, and $\mathrm{V}^{1} \mathrm{~b}$ and $\mathrm{V}^{2} \mathrm{c}$ for anterior $\mathrm{S}^{3}$ segmentectomy. (Right) The recommended approach to intersegmental veins according to the anatomic model. $\mathrm{V}^{1} \mathrm{~b}$ can usually be identified by an anterior approach except for central III type, for which a posterobronchial approach is necessary. Similarly, $\mathrm{V}^{2} \mathrm{a}$ is usually identified by the posterobronchial approach, except for anterior II-D3 type, for which an anterior approach is necessary. In addition, $\mathrm{V}^{2} \mathrm{c}$ can usually be identified by an interlobar approach, except for anterior II-E type, for which a posterobronchial approach is necessary. RUL, Right upper lobe; Ant. V, anterior vein; Cent. $V$, central vein.

for patients with emphysematous lung or interstitial lung disease, or intraoperatively when the demarcation line of the intersegmental plane was unclear.

Regarding lymph node dissection, sampling of the lymph nodes related to the resected segment was performed to determine the presence of malignancy in patients with lung cancer ( $\mathrm{LN} 11 \mathrm{~s}, 12 \mathrm{u}$, or 13). LN $12 \mathrm{u}$ and 13 are usually dissected before encircling the targeted segmental bronchus. When a lymph node was positive for malignancy, the procedure was changed to lobectomy provided that the patient could tolerate it.

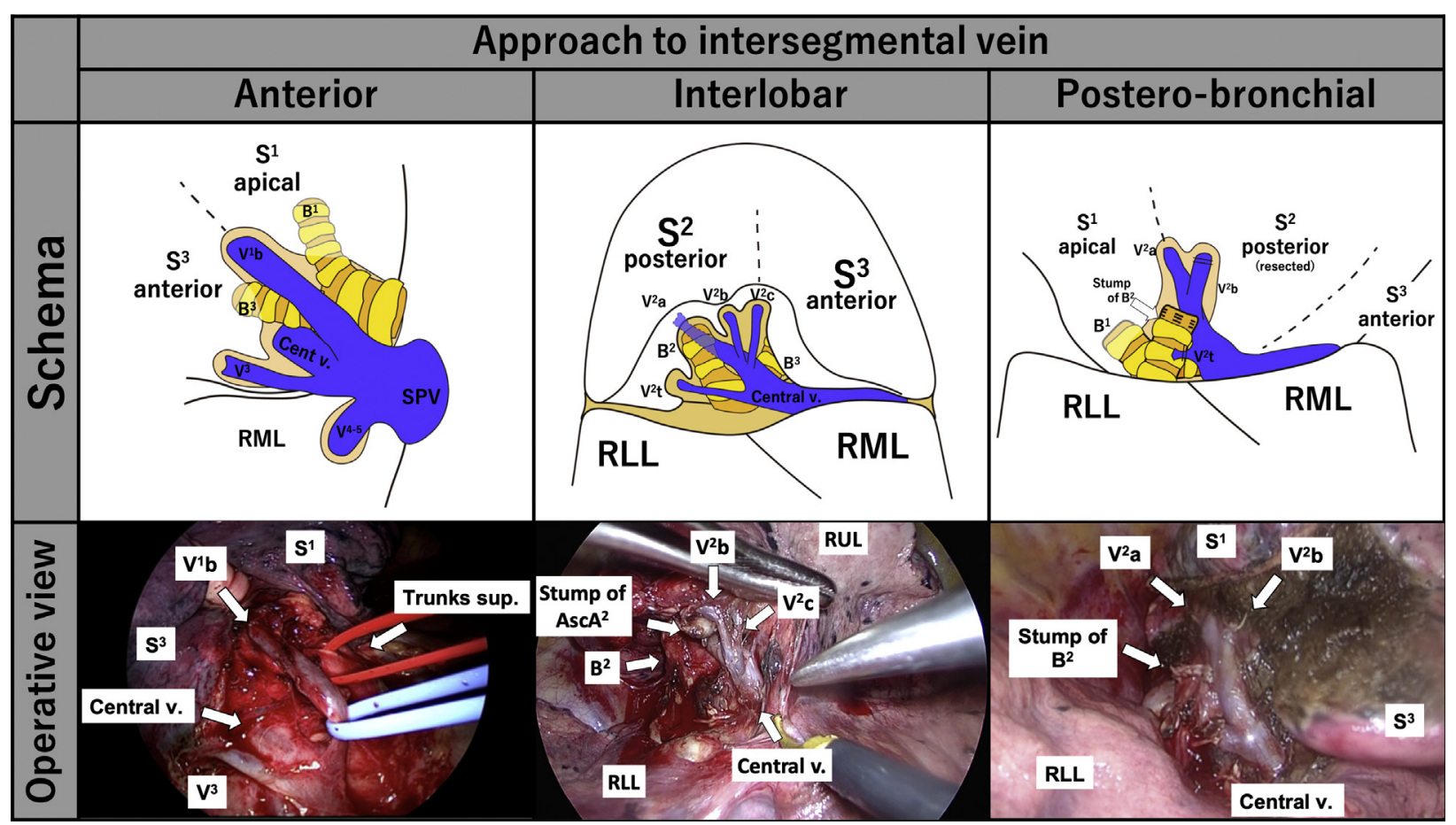

FIGURE 5. Three basic approaches to identifying intersegmental veins. Anterior approach (left column): identification of intersegmental vein $\left(\mathrm{V}^{1} \mathrm{~b}\right)$ by dissecting along the anterior part of the hilum. Interlobar approach (central column): identification of intersegmental vein $\left(\mathrm{V}^{2} \mathrm{c}\right)$ by dissecting from the interlobar fissure along either the central vein or $\mathrm{V}^{2}$ t. Posterobronchial approach (right column): identification of intersegmental vein $\left(\mathrm{V}^{2}\right.$ a) located posterior to the bronchus, usually after dissection of the targeted bronchus $\left(\mathrm{B}^{2}\right)$. Cent $v$., Central vein; $S P V$, superior pulmonary vein; $R U L$, right upper lobe; $R M L$, right middle lobe; $R L L$, right lower lobe; Trunks sup., trunks superior; $A s c A^{2}$, ascending $\mathrm{A}^{2}$. 


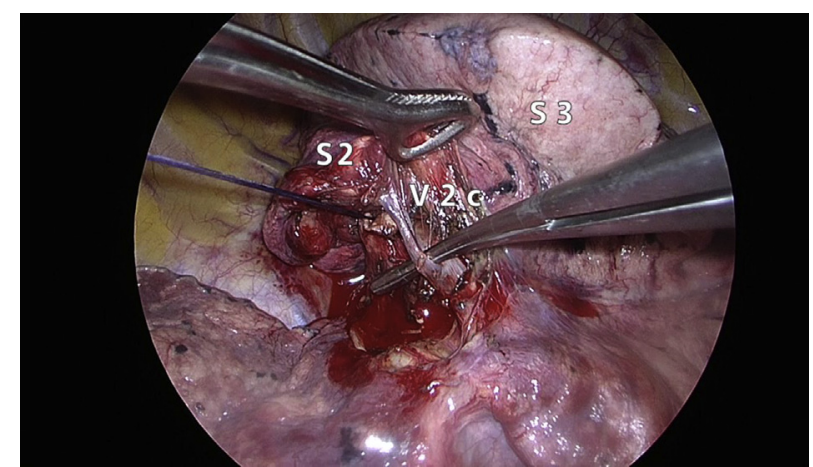

VIDEO 1. Posterior $S^{2}$ segmentectomy in a patient with anterior + central Ib-A type anatomy. First, the ascending $\mathrm{A}^{2}$ was dissected from the interlobar side, followed by dissection of the recurrent $A^{2}$ at the hilum. Then the intersegmental vein $\mathrm{V}^{2} \mathrm{c}$, defining the posteroanterior $\left(\mathrm{S}^{2}-\mathrm{S}^{3}\right)$ plane, was identified by the interlobar approach. The intersegmental vein $\mathrm{V}^{2} \mathrm{a}$, which defines the apicoposterior $\left(S^{1}-S^{2}\right)$ plane, was identified by the posterobronchial approach after resection of the $\mathrm{B}^{2}$ bronchus. The peripheral part of the $S^{2}-S^{3}$ intersegmental plane was dissected by electrocautery along the demarcation line toward $\mathrm{V}^{2} \mathrm{c}$. Similarly, the $\mathrm{S}^{1}-\mathrm{S}^{2}$ intersegmental plane was dissected by electrocautery toward $\mathrm{V}^{2} \mathrm{a}$. The remaining central part of the intersegmental plane was dissected using a stapler. Video available at: https://www.jtcvs.org/article/S2666-2507(20)30393-X/fulltext.

\section{Statistical Analysis}

Data are shown as median (interquartile range) for continuous variables and as number (\%) for categorical variables. Statistical analysis was performed using SPSS version 24 (IBM, Armonk, NY).

\section{RESULTS}

Thirty-nine patients underwent RUL segmentectomy at Gunma University between January 2016 and December 2019. Five of the patients were excluded from our analysis, including 1 patient who had undergone concurrent

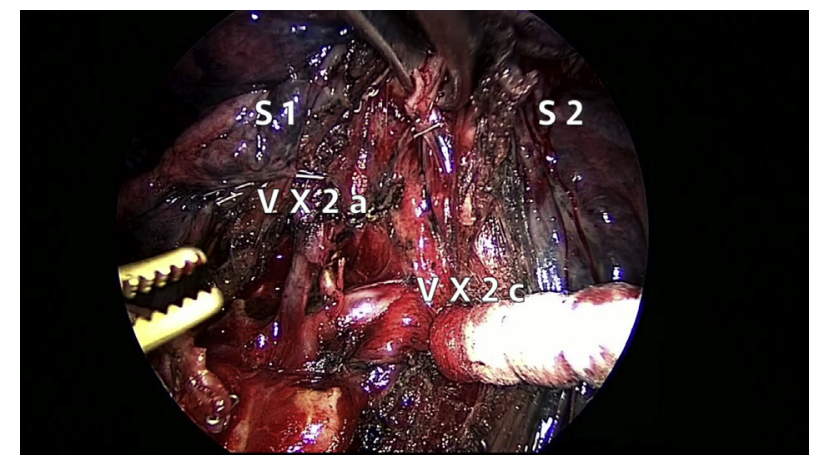

VIDEO 2. Posterior $S^{2}$ segmentectomy in an emphysematous patient with anterior II-E type anatomy. First, the ascending $\mathrm{A}^{2}$ was dissected from the interlobar side, followed by dissection of the recurrent $\mathrm{A}^{2}$ at the hilum. The intersegmental veins $\mathrm{V}^{2} \mathrm{a}\left(\mathrm{VX}^{2} \mathrm{a}\right)$ and $\mathrm{V}^{2} \mathrm{c}\left(\mathrm{VX}^{2} \mathrm{c}\right)$ were identified by the posterobronchial approach after resection of the $\mathrm{B}^{2}$ bronchus. The posteroanterior $\left(\mathrm{S}^{2}-\mathrm{S}^{3}\right)$ plane was dissected with a stapler from the periphery toward $\mathrm{VX}^{2}$ c. Similarly, the apicoposterior $\left(\mathrm{S}^{1}-\mathrm{S}^{2}\right)$ plane was dissected with a stapler along $\mathrm{VX}^{2}$ a. Video available at: https://www.jtcvs.org/article/ S2666-2507(20)30393-X/fulltext. preoperative CT-guided marking, 3 patients because of an open approach, and 1 patient because of no anatomic model guidance owing to contrast agent allergy. A final cohort of 34 patients $(87 \%)$ who underwent anatomic modelguided RUL segmentectomy were analyzed. As detailed in Table 1, this cohort included 23 males and 11 females, with a median patient age of 70 years (IQR, 66-76 years). Among the included patients, $74 \%(n=25)$ had a pathological diagnosis of lung cancer, most of which were adenocarcinomas presenting as pure ground-glass nodules $(n=9)$ or part-solid nodules $(\mathrm{n}=13)$. The remaining 3 patients with lung cancer with a solid appearance underwent segmentectomy owing to compromised cardiopulmonary function, which prevented them from undergoing lobectomy. The diagnosis was lung metastasis in 7 patients $(21 \%)$, and granuloma in 2 patients $(6 \%)$. The median tumor size was $1.6 \mathrm{~cm}$ for lung tumors (IQR, $1.4-2.2 \mathrm{~cm}$ ), $1.8 \mathrm{~cm}$ for metastatic tumors (IQR, $1.4-2.3 \mathrm{~cm}$ ), and $4.1 \mathrm{~cm}$ for granulomas (IQR, 3.7-4.6 cm). Complete pathological resection was confirmed in all patients. Regarding lymph node

TABLE 1. Patient characteristics

\begin{tabular}{|c|c|}
\hline Characteristic & Value \\
\hline Age (y), median (IQR) & $70(66-76)$ \\
\hline \multicolumn{2}{|l|}{ Sex, n $(\%)$} \\
\hline Male & $23(68)$ \\
\hline Female & $11(32)$ \\
\hline \multicolumn{2}{|l|}{ Anatomic pattern, n (\%) } \\
\hline Anterior + central Iab type & $16(47)$ \\
\hline Anterior + central Ib type & $14(41)$ \\
\hline Anterior II type & $4(12)$ \\
\hline Central III type & $0(0)$ \\
\hline \multicolumn{2}{|l|}{ Main location of lesion, $\mathrm{n}(\%)$} \\
\hline$S^{1}$ & $9(26)$ \\
\hline $\mathrm{S}^{2}$ & $13(38)$ \\
\hline$S^{3}$ & $12(35)$ \\
\hline \multicolumn{2}{|l|}{ Comorbidities, $\mathrm{n}(\%)$} \\
\hline COPD & $12(35)$ \\
\hline Diabetes mellitus & $3(9)$ \\
\hline Cardiovascular disease & $4(12)$ \\
\hline Autoimmune disease & $1(3)$ \\
\hline \multicolumn{2}{|l|}{ Preoperative diagnosis, $\mathrm{n}(\%)$} \\
\hline Lung cancer & $25(74)$ \\
\hline Metastasis & $7(21)$ \\
\hline Benign tumor & $2(6)$ \\
\hline $\begin{array}{l}\text { Consolidation/tumor ratio (lung cancer), } \\
\text { median (IQR) }\end{array}$ & $0.2(0-0.4)$ \\
\hline \multicolumn{2}{|l|}{ Pathological diagnosis, $\mathrm{n}(\%)$} \\
\hline Lung cancer & $25(74)$ \\
\hline Adenocarcinoma & $22(65)$ \\
\hline Squamous cell carcinoma & $3(9)$ \\
\hline Metastasis & $7(21)$ \\
\hline Granuloma & $2(6)$ \\
\hline
\end{tabular}

$I Q R$, Interquartile range; $C O P D$, chronic obstructive pulmonary disease. 
evaluation, 17 patients $(50 \%)$ underwent sampling at 1 station (usually LN 12u or 13), 7 (21\%) underwent sampling at more than 2 stations (LN $10,11 \mathrm{~s}, 12 \mathrm{u}$, or 13$)$, and $2(6 \%)$ underwent mediastinal lymph node dissection (LN 2R and $4 \mathrm{R}$ ). All dissected lymph nodes were negative for metastasis.

As shown in Table 2, the median operative time was 222 minutes (IQR, 202-242 minutes), and the median intraoperative blood loss was $19 \mathrm{~g}$ (IQR, 7-49 g). The median duration of chest tube insertion and postoperative hospital stay was 2 days (IQR, 2-3 days) and 7 days (IQR, 69 days), respectively. Prolonged postoperative air leak exceeding 7 days was noted in 1 patient, for which adhesion therapy was performed. The median duration of follow-up was 13 months (IQR, 5-19 months). Although none of the patients with lung cancer developed locoregional recurrence, 1 patient who underwent segmentectomy for compromised lung function died from brain metastasis. Among the 7 patients who underwent segmentectomy for metastatic lung lesions, 4 were undergoing treatment for new metastatic lesions at the time of this report.

All patients could be classified into 1 of the 4 anatomic models (Table 1): 16 patients $(47 \%)$ with the anterior + central Iab type, $14(41 \%)$ with the anterior + central $\mathrm{Ib}$ type, and $4(12 \%)$ with the anterior II type. No patient had the central III type. Aberrant $\mathrm{V}^{2}$ was present in 1 patient with anterior + central Iab type, who had $2 \mathrm{~V}^{2}$ a, one draining into the aberrant $\mathrm{V}^{2}$ and the other draining into the usual central vein. Tumors were located mainly at the $S^{1}$ segment in 9 patients, the $S^{2}$ segment in 13 patients, and the $S^{3}$ segment in 12 patients (Tables 1 and 3). Single segmentectomy was the most common procedure $(n=26 ; 76 \%)$; bisegmentectomy was performed in 1 patient $(3 \%)$, segmentectomy combined with subsegmentectomy was performed in 4 patients $(12 \%)$, bisubsegmentectomy was performed in 3 patients $(9 \%)$, and subsegmentectomy alone was performed in 1 patient $(3 \%)$.

The method of approach for identifying the intersegmental or intrasegmental veins was changed from a standard approach according to the anatomic subtype in 4 cases $(12 \%)$. For example, $\mathrm{V}^{2} \mathrm{c}$ was usually identified by

TABLE 2. Surgical results

\begin{tabular}{lc}
\hline \multicolumn{1}{c}{ Characteristic } & Value \\
\hline Operative time (minutes), median (IQR) & $222(202-242)$ \\
Bleeding (grams), median (IQR) & $19(7-49)$ \\
Chest tube duration (d), median (IQR) & $2(2-3)$ \\
Postoperative hospital stay (d), median (IQR) & $7(6-9)$ \\
Complications, n (\%) & \\
$\quad$ Prolonged air leak (>7 d) & $1(3)$ \\
Elevated liver enzymes & $1(3)$ \\
$90-$ d mortality, n $(\%)$ & $0(0)$ \\
\hline
\end{tabular}

$I Q R$, Interquartile range.
TABLE 3. Details of anatomic model type and resected segments

\begin{tabular}{|c|c|c|c|}
\hline $\begin{array}{c}\text { Main location } \\
\text { of lesion }\end{array}$ & $\begin{array}{l}\text { Anatomic model } \\
\text { type (subtype) }\end{array}$ & Segmentectomy & Number \\
\hline \multirow{8}{*}{$S^{1}(n=9)$} & $\mathrm{Iab}(\mathrm{A} / \mathrm{B} / \mathrm{C})$ & $S^{1}$ & $2(1 / 1 / 0)$ \\
\hline & & $S^{1} a+S^{2} b$ & $1(1 / 0 / 0)$ \\
\hline & & $S^{1} a+S^{2}$ & $1(0 / 0 / 1)$ \\
\hline & & $S^{1}+S^{2}$ & $1(1 / 0 / 0)$ \\
\hline & $\mathrm{Iab}+$ aberrant $\mathrm{V}^{2}$ & $S^{1}$ & 1 \\
\hline & & $S^{1} a+S^{2}$ & 1 \\
\hline & $\mathrm{Ib}(\mathrm{A} / \mathrm{B} / \mathrm{C})$ & $S^{1}$ & $1(0 / 0 / 1)$ \\
\hline & II (E) & $S^{1}$ & 1 \\
\hline \multirow[t]{6}{*}{$S^{2}(n=13)$} & $\mathrm{Iab}(\mathrm{A} / \mathrm{B} / \mathrm{C})$ & $S^{2}$ & $3(2 / 1 / 0)$ \\
\hline & & $S^{1} a+S^{2}$ & $1(1 / 0 / 0)$ \\
\hline & $\mathrm{Ib}(\mathrm{A} / \mathrm{B} / \mathrm{C})$ & $S^{2}$ & $6(4 / 1 / 1)$ \\
\hline & & $S^{1} a+S^{2}$ & $1(1 / 0 / 0)$ \\
\hline & II (D1/D2/D3/E) & $S^{2}$ & $1(0 / 0 / 0 / 1)$ \\
\hline & & $S^{2} b+S^{3} a$ & $1(1 / 0 / 0 / 0)$ \\
\hline \multirow[t]{4}{*}{$S^{3}(n=12)$} & Iab (A/B/C) & $\mathrm{S}^{3}$ & $4(2 / 1 / 1)$ \\
\hline & & $S^{3} b$ & $1(1 / 0 / 0)$ \\
\hline & $\mathrm{Ib}(\mathrm{A} / \mathrm{B} / \mathrm{C})$ & $S^{3}$ & $5(3 / 1 / 1)$ \\
\hline & II (D1/D2/D3/E) & $S^{3}$ & $2(1 / 0 / 1 / 0)$ \\
\hline
\end{tabular}

an interlobar approach, tracking along the central vein in a peripheral direction (Figure 6, $A-C$ ). However, in anterior II-E type $(2.8 \%),{ }^{11} \mathrm{~V}^{2} \mathrm{c}$ runs within the lung parenchyma and drains into the anterior vein. Therefore, in patients with anterior II-E type, $\mathrm{V}^{2} \mathrm{c}$ was identified through the posterobronchial approach after segmental bronchus resection (Figure 6, $D-F$ ).

\section{DISCUSSION}

In the present study, we evaluated the clinical outcome of anatomic model-guided RUL segmentectomy. Our findings can be summarized as follows: (1) all patients could be classified into 1 of the RUL anatomic models; (2) the approach for identifying intersegmental veins was simplified and standardized into 3 approaches: anterior, interlobar, and posterobronchial; (3) the appropriate approach for intersegmental veins was selected based on the anatomic model and differed from the standard approach in some anatomic models; and (4) the short- and long-term outcomes were acceptable.

Previous anatomic studies have extensively analyzed the lung anatomy to a subsegmental level. ${ }^{8}$ However, the sophisticated knowledge of RUL anatomy has not been efficiently implemented into the surgical field, especially in those related to segmentectomies. As reported previously, RUL anatomy can be classified as 1 of the 14 anatomic models in $93.8 \%$ of cases. ${ }^{11}$ In this study, there were no patients with central III type, likely because of the overall low 
A

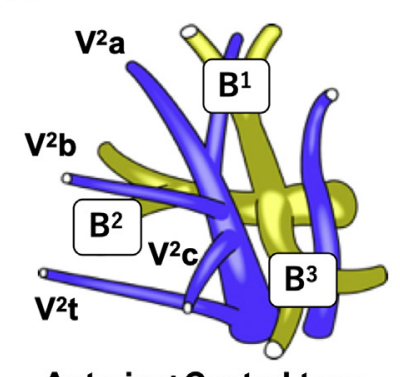

Anterior+Central type

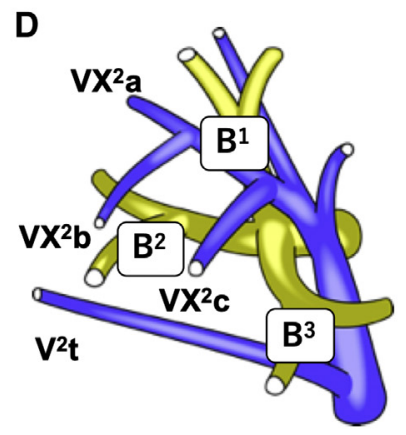

Anterior II-E type
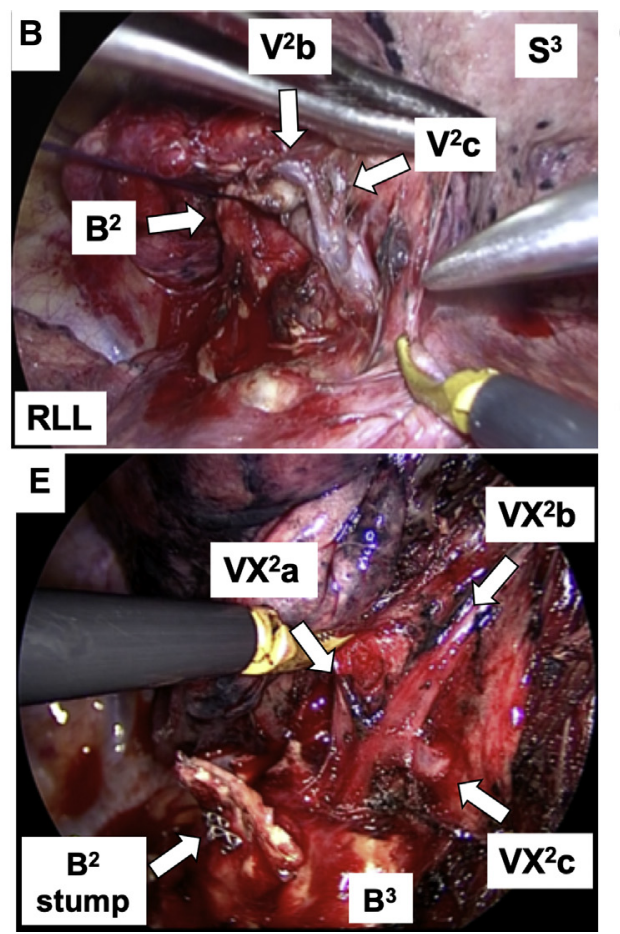

C

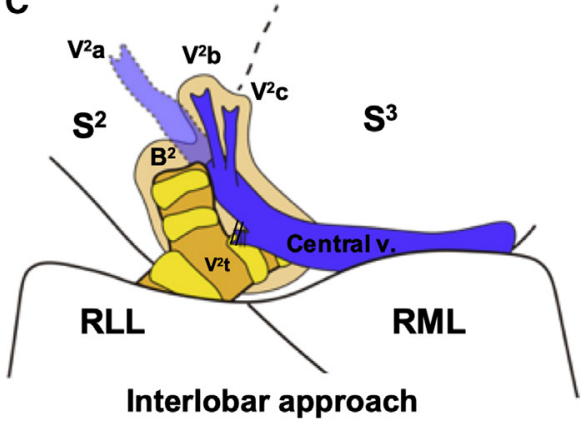

$\mathbf{F}$

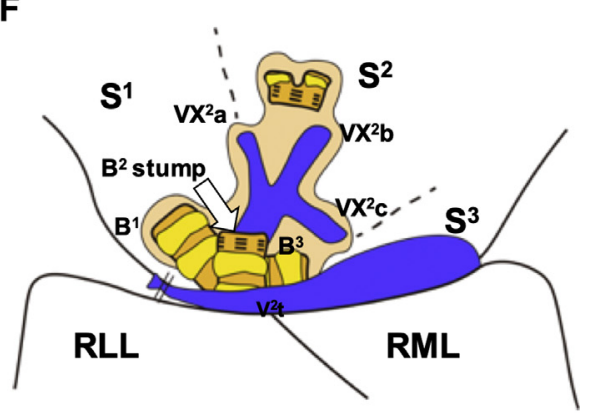

Postero-bronchial approach

FIGURE 6. Different approaches for the $\mathrm{V}^{2} \mathrm{c}$ intersegmental vein according to anatomic model subtype during $\mathrm{S}^{2}$ segmentectomy. A to $\mathrm{C}$, The $\mathrm{V}^{2} \mathrm{c}$ intersegmental vein, delineating the posteroanterior $\left(S^{2}-S^{3}\right)$ plane, usually drains into the central vein after running along the interlobar fissure. Therefore, $V^{2} \mathrm{c}$ was identified by tracking along the central vein in a peripheral direction for anterior + central Iab and $\mathrm{Ib}$ types and central III type, or along $\mathrm{V}^{2} \mathrm{t}$ for anterior II-D type (interlobar approach). D to F, For anterior II-E type, $\mathrm{V}^{2} \mathrm{c}\left(\mathrm{VX}^{2} \mathrm{c}\right)$ ran within the lung parenchyma and finally drained into the anterior vein. Thus, it could not be observed from the interlobar fissure but was only identified after resection of the $\mathrm{B}^{2}$ segmental bronchus (posterobronchial approach). $R L L$, Right lower lobe; central v., central vein; RML, right middle lobe.

incidence of this type $(7 \%) .{ }^{11}$ Moreover, the incidence of lung lesions was almost equivalent for each segment ( $26 \%$ for $\mathrm{S}^{1}, 38 \%$ for $\mathrm{S}^{2}$, and $35 \%$ for $\mathrm{S}^{3}$ ), suggesting that surgeons should be equally prepared for every type of RUL segmentectomy.

Theoretically, the method of approach for RUL intersegmental veins might differ from the standard approach in $6.3 \%$ to $10.5 \%$ of cases (Figure 4 ; Table 4 ). The incidence might be higher when the procedure involves a subsegmentectomy, which is affected by variations in both intersegmental and intrasegmental veins. As described in above, the approach for $\mathrm{V}^{2} \mathrm{c}$ differed in the anterior II-E type. Similarly, $\mathrm{V}^{2}$ a usually can be identified using the posterobronchial approach; however, for anterior II-D3 type $(3.5 \%),{ }^{11} \mathrm{~V}^{2} \mathrm{a}$ ran on the mediastinal side at the surface of the lung parenchyma and was identified using the anterior approach. Furthermore, $\mathrm{V}^{1} \mathrm{~b}$ usually can be identified using the anterior approach; however, for central III type $(7 \%),{ }^{11} \mathrm{~V}^{1} \mathrm{~b}$ ran within the lung parenchyma and was identified using the posterobronchial approach.

Several limitations of this study are worth noting. First, it a retrospective analysis with a small sample size and has a

TABLE 4. Theoretical incidence of change in approach to intersegmental veins according to the anatomic model

\begin{tabular}{|c|c|c|c|c|}
\hline $\begin{array}{c}\text { Target } \\
\text { segment }\end{array}$ & Intersegmental vein & $\begin{array}{l}\text { Standard } \\
\text { approach }\end{array}$ & Change in approach according to subtype & $\begin{array}{c}\text { Theoretical } \\
\text { incidence }(\%)\end{array}$ \\
\hline $\mathrm{S}^{1}$ & $\begin{array}{l}\mathrm{V}^{1} \mathrm{~b} \\
\mathrm{~V}^{2} \mathrm{a}\end{array}$ & $\begin{array}{l}\text { Anterior } \\
\text { Posterobronchial }\end{array}$ & $\begin{array}{l}\text { Posterobronchial approaching central III type }(7 \%) \\
\text { Anterior approach in anterior II-D3 type }(3.5 \%)\end{array}$ & 10.5 \\
\hline$S^{2}$ & $\begin{array}{l}V^{2} \mathrm{a} \\
\mathrm{V}^{2} \mathrm{c}\end{array}$ & $\begin{array}{l}\text { Posterobronchial } \\
\text { Interlobar }\end{array}$ & $\begin{array}{l}\text { Anterior approach in anterior II-D3 type }(3.5 \%) \\
\text { Posterobronchial approach in anterior-E type }(2.8 \%)\end{array}$ & 6.3 \\
\hline$S^{3}$ & $\begin{array}{l}\mathrm{V}^{1} \mathrm{~b} \\
\mathrm{~V}^{2} \mathrm{c}\end{array}$ & $\begin{array}{l}\text { Anterior } \\
\text { Interlobar }\end{array}$ & $\begin{array}{l}\text { Posterobronchial approach in central III type }(7 \%) \\
\text { Posterobronchial approach in anterior-E type }(2.8 \%)\end{array}$ & 9.8 \\
\hline
\end{tabular}




\section{Right upper lobe segmentectomy guided by anatomic models with model-based approach to intersegmental veins}

\begin{tabular}{|c|c|c|c|c|c|}
\hline \multicolumn{5}{|c|}{$\begin{array}{c}\text { Anatomic pattern and recommended approach for } \\
\text { intersegmental veins }\end{array}$} & \multirow{6}{*}{$\begin{array}{l}\text { - Anatomic model-guided } \\
\text { segmentectomy was } \\
\text { performed in } 34 \text { patients. } \\
\\
\text { - The standard method of } \\
\text { approach for } \mathrm{V}^{1} \mathrm{~b}, \mathrm{~V}^{2} \mathrm{a} \text {, and } \\
\mathrm{V}^{2} \mathrm{c} \text { were anterior, postero- } \\
\text { bronchial, and interlobar } \\
\text { approach, respectively. } \\
\text { - The method of approach to } \\
\text { segmental veins was } \\
\text { changed from a standard } \\
\text { one according to the } \\
\text { anatomic subtype in } 12 \% \\
\text { of cases }\end{array}$} \\
\hline Type & $\begin{array}{c}\text { Anterior + Central } \\
\text { lab type }\end{array}$ & $\begin{array}{c}\text { Anterior + Central } \\
\text { Ib type }\end{array}$ & Anterior II type & Central III type & \\
\hline$\frac{\text { ర }}{\frac{E}{0}}$ & Cent. $v$ Ant. $v$ & Cent. $v$ Ant. v & & Cent. $v$ & \\
\hline $\mathrm{V}^{1} \mathbf{b}$ & \multicolumn{3}{|c|}{ Anterior } & Postero-bronchial & \\
\hline$V^{2} a$ & \multicolumn{2}{|c|}{ Postero-bronchial } & $\begin{array}{l}\text { D3 subtype: anterior } \\
\text { Others: postero- } \\
\text { bronchial }\end{array}$ & Postero-bronchial & \\
\hline $\mathrm{V}^{2} \mathrm{c}$ & \multicolumn{2}{|c|}{ Interlobar } & $\begin{array}{c}\text { E subtype: postero- } \\
\text { bronchial } \\
\text { Others: interlobar }\end{array}$ & Interlobar & \\
\hline
\end{tabular}

FIGURE 7. Right upper lobe (RUL) segmentectomy guided by a simplified anatomic model consisting of (1) a 2-step classification of the segmental anatomy into 1 of the 14 anatomic models and (2) a standardized approach to intersegmental veins selected according to the anatomic model. This method led to the successful classification and completion of RUL segmentectomy in 34 consecutive patients. Cent. V, Central vein; Ant. V, anterior vein.

selection bias. Therefore, we did not encounter all types of anatomic variations. Regarding minor but important variations of the bronchi, such as the defective $\mathrm{B}^{1}$ type, ${ }^{9}$ for which the $\mathrm{B}^{1}$ a bronchus branches from $\mathrm{B}^{2}$ and the $\mathrm{B}^{1} \mathrm{~b}$ bronchus branches from $\mathrm{B}^{3}$, our surgical strategy is applicable if it can be classified into 1 of the nearest analog subtypes. Second, patients with aberrant $\mathrm{V}^{2}(2.2 \%)$ might not have the usual intersegmental veins, $\mathrm{V}^{2} \mathrm{a}$ and/or $\mathrm{V}^{2} \mathrm{c}$. In such a case, identification of the intersegmental plane should be guided not by intersegmental veins alone, but in combination with other adjuncts. Third, in our previous analysis, ${ }^{9,10}$ several patients had veins that crossed over segments with no usual intersegmental veins and could not be classified into our anatomic models. Although we did not encounter such patients during this study period, we would not recommend RUL anatomic segmentectomy for them, because they are likely to have atypical intersegmental borders and/or lobulation.

\section{CONCLUSIONS}

The present study demonstrates that converting the RUL anatomy into simplified anatomic models helps elucidate the spatial relationship between segmental bronchi and intersegmental veins, which is an essential component of 3D-CT-guided anatomic segmentectomy. Furthermore, classification into anatomic models aids the precise classification and development of a standardized approach to identifying intersegmental veins, even for cases with anatomic variation (Figure 7). We believe that the use of simplified anatomic models will allow for increased implementation of anatomic RUL segmentectomy.

\section{Conflict of Interest Statement}

The authors reported no conflicts of interest.

The Journal policy requires editors and reviewers to disclose conflicts of interest and to decline handling or reviewing manuscripts for which they may have a conflict of interest. The editors and reviewers of this article have no conflicts of interest.

We thank Yasuhiro Fukushima, Junya Fukuda, and Hiroyuki Takei (Department of Radiology, Gunma University Hospital) for obtaining the 3D-CT images. We also thank Takeshi Araki (Gunma University Hospital) for his support in creating the illustrations used in this article.

\section{References}

1. Okami J, Shintani Y, Okumura M, Ito H, Ohtsuka T, Toyooka S, et al. Demographics, safety and quality, and prognostic information in both the seventh and eighth editions of the TNM classification in 18,973 surgical cases of the Japanese joint committee of lung cancer registry database in 2010. J Thorac Oncol. 2019;14:212-22.

2. de Koning HJ, van der Aalst CM, de Jong PA, Scholten ET, Nackaerts K, Heuvelmans MA, et al. Reduced lung-cancer mortality with volume CT screening in a randomized trial. N Engl J Med. 2020;382:503-13.

3. Andolfi M, Potenza R, Seguin-Givelet A, Gossot D. Identification of the intersegmental plane during thoracoscopic segmentectomy: state of the art. Interact Cardiovasc Thorac Surg. 2020;30:329-36.

4. Bédat B, Abdelnour-Berchtold E, Krueger T, Perentes JY, Zellweger M, Triponez F, et al. Impact of complex segmentectomies by video-assisted thoracic surgery on peri-operative outcomes. J Thorac Dis. 2019;11:4109-18.

5. Shimizu K, Nakano T, Kamiyoshihara M, Takeyoshi I. Segmentectomy guided by three-dimensional computed tomography angiography and bronchography. Interact Cardiovasc Thorac Surg. 2012;15:194-6.

6. Nakazawa S, Shimizu K, Mogi A, Kuwano H. VATS segmentectomy: past, present, and future. Gen Thorac Cardiovasc Surg. 2018;66:81-90.

7. Ohtaki Y, Shimizu K. Anatomical thoracoscopic segmentectomy for lung cancer. Gen Thorac Cardiovasc Surg. 2014;62:586-93.

8. Yamashita H. Roentgenologic Anatomy of the Lung. New York: Igaku-Shoin; 1978:389. 
9. Nagashima T, Shimizu K, Ohtaki Y, Obayashi K, Kakegawa S, Nakazawa S, et al. An analysis of variations in the bronchovascular pattern of the right upper lobe using three-dimensional CT angiography and bronchography. Gen Thorac Cardiovasc Surg. 2015;63:354-60.

10. Nagashima T, Shimizu K, Ohtaki Y, Obayashi K, Nakazawa S, Mogi A, et al. Analysis of variation in bronchovascular pattern of the right middle and lower lobes of the lung using three-dimensional CT angiography and bronchography. Gen Thorac Cardiovasc Surg. 2017;65:343-9.

11. Shimizu K, Nagashima T, Ohtaki Y, Obayashi K, Nakazawa S, Kamiyoshihara $\mathrm{M}$, et al. Analysis of the variation pattern in right upper pulmonary veins and establishment of simplified vein models for anatomical segmentectomy. Gen Thorac Cardiovasc Surg. 2016;64: 604-11.

12. Asamura H, Hishida T, Suzuki K, Koike T, Nakamura K, Kusumoto M, et al. Radiographically determined noninvasive adenocarcinoma of the lung: survival outcomes of Japan clinical oncology group 0201. J Thorac Cardiovasc Surg. 2013;146:24-30.

13. Suzuki K, Koike T, Asakawa T, Kusumoto M, Asamura H, Nagai K, et al. A prospective radiological study of thin-section computed tomography to predict pathological noninvasiveness in peripheral clinical IA lung cancer (Japan clinical oncology group 0201). J Thorac Oncol. 2011;6:751-6.

14. Sawabata N, Nagayasu T, Kadota Y, Goto T, Horio H, Mori T, et al. Risk assessment of lung resection for lung cancer according to pulmonary function: republication of systematic review and proposals by guideline committee of the Japanese Association for Chest Surgery 2014. Gen Thorac Cardiovasc Surg. 2015;63:14-21.

Key Words: segmentectomy, right upper lobe, 3D-CT, classification, anatomic model 